\title{
Participating in a Health Promotion Program in Pediatric Oncology: Perspectives of Children, Adolescents and Families
}

Catherine Demers ( $\square$ catherine.demers@mail.mcgill.ca )

CHU Sainte-Justine: Centre Hospitalier Universitaire Sainte-Justine https://orcid.org/0000-0001-75049843

\section{Isabelle Gélinas}

McGill University

Keven Lee

McGill University

Claude Julie Bourque

CHU Ste-Justine

Kristopher Lamore

Université Paris Descartes

Daniel Curnier

Université de Montréal

Valérie Marcil

Université de Montréal

\section{Serge Sultan}

Université de Montréal

\section{Daniel Sinnett}

CHU Ste-Justine

Johanne Higgins

Université de Montréal: Universite de Montreal

\section{Research Article}

Keywords: pediatric oncology, barriers, health promotion, healthy behaviours

Posted Date: November 30th, 2021

DOI: https://doi.org/10.21203/rs.3.rs-962537/v1

License: (a) (i) This work is licensed under a Creative Commons Attribution 4.0 International License.

Read Full License 


\section{Abstract}

Purpose. Health promotion (HP) programs represent a promising avenue to address the prevention or mitigation of adverse effects of childhood cancer. However, we do not know the most effective way to promote healthy behaviours in pediatric oncology or how families experience HP interventions during the very challenging time of going through childhood cancer. The purpose of this study was to analyse the perspectives of families affected by childhood cancer regarding their behaviour when participating in a HP program.

Methods. We undertook a cross-sectional qualitative study using semi-structured interviews. Individual interviews were conducted with parents and adolescents sampled within a larger study. Data was analyzed using thematic analysis.

Results. Participants reported many barriers to participation including organizational barriers, physical or mental health issues and lack of interest or need. Key facilitators included tailoring of the interventions to individuals' needs and social support. Most participants reported that the program had a positive impact on their health behaviour practices during cancer treatment and about half mentioned having the intention to modify their health behaviour practices in the long-term. For future implementation, participants suggested adding more educational activities, increasing physical activity sessions and improving the coordination with clinical activities.

Conclusion. Participants' and families' perspectives allow researchers and clinicians to gain greater insights into how to shape HP programs that will be engaging and effective in promoting healthy behaviours in this population.

\section{Background}

As a constantly increasing number of children and adolescents are surviving cancer, there has been a paradigm shift in pediatric oncology from attaining survival at all costs to survival with optimal quality of life. There is evidence that survivors of childhood cancers are at significantly greater risk of suffering from various adverse effects secondary to cancer and its treatment [1-4]. Consequently, researchers and clinicians have highlighted the importance of developing and testing innovative interventions aiming at reducing the impact of these adverse effects [5-7] and supporting children affected by cancer throughout their journey (i.e., from diagnosis to survivorship). One area of study that has gained popularity in the pediatric oncology literature in the last decade is health prevention and promotion. Health promotion (HP) interventions represent a promising avenue to address the prevention or mitigation of childhood cancer's adverse effects [8], particularly for cardiometabolic complications, osteoporosis and diabetes, which are prevalent in this population $[9,10]$. As reviewed by Demark-Wahnefried and colleagues [11], there is developing literature on lifestyle interventions in pediatric oncology that focus on health behaviours such as diet, exercise, tobacco control and sun protection. Health behaviours in are known to be to negatively affected by cancer diagnosis and treatments [12-14], but positively impacted by HP interventions [15, 
16]. A recent review provided evidence that complex behavioural interventions targeting physical activity and/or nutrition in pediatric oncology are feasible and potentially beneficial to improve the health behaviours and outcomes of children affected by cancer and survivors [17]. Identifying the factors that influence the adoption of healthy behaviours of children affected by cancer is essential for the development and implementation of effective interventions to improve their health and well-being [18]. However, the literature in the field remains scarce.

As HP in pediatric oncology is a new field of study, we lack knowledge on effective way to promote healthy behaviours or how families experience HP interventions while going through childhood cancer. There is a need for qualitative or mixed methods studies in the field [17] to better understand how to support a level of behaviour change that is sufficient to improve clinical outcomes and sustainable. In addition, qualitative studies could shed light on how participants experience innovative interventions which cannot be captured by questionnaires or quantitative studies. The purpose of this qualitative study is to analyse the perspectives of children or adolescents affected by cancer and their families regarding their behaviour when participating in a HP program. This will allow to gain insight into the implementation process and future refinement of the HP program and, more generally, to determine which factors can facilitate or hamper behaviour change.

\section{Methods}

\section{Clinical context}

The present study was part of a non-randomized feasibility study conducted at the Charles Bruneau Cancer Center (CBCC), Sainte-Justine University Hospital Center (SJUHC), Montreal, Canada. The VIE (Valorization, Implication, Education) study consists of a two-year family-oriented multidisciplinary interventional program. The program, delivered between January 2018 and December 2021, integrates psychosocial support, nutrition counselling and physical activity interventions [19]. The objective of this program is to optimize outcomes of children affected by cancer by encouraging the adoption of health behaviours. Parents and children newly diagnosed with cancer and treated at SJUHC were offered to participate in the program from January 2018 until December 2019 if they were (1) less than 21 years old at diagnosis, (2) being treated with radiation therapy or chemotherapy, (3) able to give an informed consent (by parents or legal tutors if < 18 years old), and (4) being less than 12-weeks post-diagnosis.

\section{Guiding conceptual framework}

The Theory of Planned Behavior (TPB) was used as a conceptual framework to guide the development of the interviews with study participants. According to the TPB, attitudes towards the behaviour, subjective norm and perceived behaviour control can gage the readiness of an individual to engage in that behaviour [20]. Studies have provided preliminary data that support the TPB's utility in the pediatric oncology population $[12,21]$. Furthermore, specifically to classify barriers and facilitators, we used the constructs of the Consolidated Framework for Implementation Research (CFIR) [22], arranged across five domains (i.e., intervention characteristics, outer setting, inner setting, characteristics of individuals, 
process). See Table 1 for a description of each domain. The CFIR was developed by implementation researchers and provides a practical guide for systematically assessing barriers and facilitators for implementing innovation strategies. We chose to use the CFIR at the beginning of the data analysis phase as it is one of the most recognized frameworks for assessing barriers and facilitators and as categories that emerged during data analysis clearly aligned with the ones outlined in the framework.

Table 1

Consolidated Framework for Implementation Research domains [22]

\begin{tabular}{|ll|}
\hline CFIR domain & Description \\
\hline $\begin{array}{l}\text { Intervention } \\
\text { characteristics }\end{array}$ & $\begin{array}{l}\text { Features an intervention that might influence implementation, including its } \\
\text { perceived internal or external origin, evidence quality and strength, relative } \\
\text { advantage, adaptability, trialability, complexity, design quality and presentation, } \\
\text { and cost. }\end{array}$ \\
\hline Inner setting & $\begin{array}{l}\text { Features of the implementing organization that might influence implementation, } \\
\text { such as team culture, compatibility and relative priority of the intervention, } \\
\text { structures for goal-setting and feedback, leadership engagement, and the } \\
\text { implementation climate. }\end{array}$ \\
\hline Outer setting & $\begin{array}{l}\text { Features of the external context or environment that might influence } \\
\text { implementation, including patient needs and resources, cosmopolitanism or the } \\
\text { level at which the implementing organization is networked with other } \\
\text { organizations, peer pressure, and external policies and incentives. }\end{array}$ \\
\hline $\begin{array}{l}\text { Imaracteristics individuals } \\
\text { Implementation } \\
\text { process }\end{array}$ & $\begin{array}{l}\text { Characteristics of individuals involved in implementation that might influence } \\
\text { implementation, including individuals' beliefs, knowledge, self-efficacy and } \\
\text { personal attributes. }\end{array}$ \\
\hline $\begin{array}{l}\text { Strategies or tactics that might influence implementation, including stages of } \\
\text { implementation such as planning, executing, reflecting and evaluating, and the } \\
\text { presence of key intervention stakeholders and influencers including opinion }\end{array}$ \\
leaders, stakeholder engagement, and project champions.
\end{tabular}

\section{Participants}

Participants in this study: 1) had been participating in the VIE study for at least 1.5 year and 2) agreed to be contacted. The first inclusion criteria ensured that participants could reflect on their experience during the different treatment phases (i.e. acute, maintainance, survivorship). A total of 34 potential families were eligible for the study and we expected to recruit a minimum of 12 families, following a recommendation from Guest, Bunce and Johnson (2006) who determined that saturation generally occurs within the first 12 interviews. Participants were contacted by telephone about their willingness to participate in the interviews. Purposive sampling was used to recruit a variety of participants across different diagnosis groups (leukemia, lymphomia, other), age groups (0-5, 6-12, $\geq 13$ years old), gender (male, female) and levels of participation (low, average or optimal). The sample was also a convenience sample to the extent that the people invited to take part were those attending the clinic when we were doing fieldwork. 
Ethical approval for this study was obtained from the SJUHC Research Ethics Board. Written informed consent was obtained from parents or adolescents $\geq 18$ years old and verbal consent for children and adolescents $<18$ years old. Data was anonymized and pseudonyms were given to participants to ensure confidentiality.

\section{Procedures}

We undertook a cross-sectional qualitative study using semi-structured individual interviews. The interviews were conducted in-person or virtually using the Zoom platform, according to participants' preference. Adolescents and parents were interviewed separately to allow each of them to express themselves freely. A semi-structured interview guideline was developed for this study based on i) literature searches, ii) the TPB, and iii) discussion with the research team and a resource patient (i.e., a young adult who works collaboratively with the research team by bringing her perspective as an expert from living with and surviving childhood cancer) to ensure its relevance. The interviews were conducted in a conversational style to create an open interaction. The order and wording of the questions were adapted to each participant and we used probes, if needed, to seek more information or for clarification. Major themes addressed were: (1) barriers and facilitators to participation in the study; (2) attitude, subjective norms, perceived behaviour control and intention to change in relation to the adoption of healthy behaviours; and (3) suggestions of strategies or recommendations that could support participation in the program and change in their behaviour. All interviews were audiotaped and transcribed verbatim by the first author (CD).

\section{Data analysis}

Descriptive statistics were used to analyse demographic and clinical characteristics of participants. In terms of qualitative data, thematic analysis was used to capture the perspective of the VIE study participants, which is a method for identifying, analyzing, and reporting patterns (themes) within data [23]. A deductive approach was chosen, using both the TPB and the CFIR to create the basic coding tree and coding definition. Data analysis was conducted by the first author (CD), then $20 \%$ of the the collected data was analyzed by an independent researcher, not involved in the research projet (KL), using NVivo software. Interater agreement was over $90 \%$ during initial coding and all discrepencies in coding were resolved by discussion.

\section{Results}

\section{Sample and clinical characteristics}

The first author (CD) conducted all interviews between November 2020 and January 2021, face-to-face $(n=12)$ or virtually $(n=2)$. Fourteen families were approached, of which two declined participation, resulting in the inclusion of 12 families (Table 2). As two families had two participants, 14 interviews were conducted. After interviewing 14 participants, saturation was considered reached; participants in later interviews did not indicate any significant new barriers or facilitator to participation. Nine 
participants were parents (five mothers, four fathers) and five were adolescents (range 14 to 20 years old). For seven families, the child affected by cancer was female (58\%) and the cancer diagnosis represented were leukemia $(n=7 ; 58 \%)$, extracranial solid tumor $(n=3 ; 25 \%)$ and lymphoma $(n=2 ; 17 \%)$. Most participants had a level of participation in the VIE study considered "average" ( $n=10 ; 83 \%)$, one a "low" level (8\%) and another one an "optimal" level (8\%). The interviews ranged in duration between 8 and $38 \mathrm{~min}$ (median $13 \mathrm{~min}$ ), as evaluated by a survey conducted with research team members who deliver the interventions. 
Table 2

Sample and clinical characteristics of participants

\begin{tabular}{|c|c|c|}
\hline Characteristics & $\begin{array}{l}\text { Adolescents }(n=5) \\
n(\%)\end{array}$ & $\begin{array}{l}\text { Parents }(n=9) \\
n(\%)\end{array}$ \\
\hline \multicolumn{3}{|l|}{ Age of the child at diagnosis (years) } \\
\hline $0-4$ & $0(0)$ & $3(33)$ \\
\hline $5-12$ & $0(0)$ & $4(44)$ \\
\hline 13 and + & $5(100)$ & $2(22)$ \\
\hline \multicolumn{3}{|l|}{ Sex of the child } \\
\hline Male & $3(60)$ & $3(33)$ \\
\hline Female & $2(40)$ & $6(67)$ \\
\hline \multicolumn{3}{|l|}{ Race/ethnicity } \\
\hline White/Caucasian & $4(80)$ & $8(89)$ \\
\hline Other & $1(20)$ & $1(11)$ \\
\hline \multicolumn{3}{|l|}{ Cancer diagnosis of the child } \\
\hline Leukemia & $3(60)$ & $5(56)$ \\
\hline Lymphoma & $1(20)$ & $1(11)$ \\
\hline Central Nervous System Tumors & $0(0)$ & $0(0)$ \\
\hline Extra cranial solid tumor & $1(20)$ & $3(33)$ \\
\hline \multicolumn{3}{|l|}{ Participation level of the child* } \\
\hline Low & $1(20)$ & $0(0)$ \\
\hline Average & $4(80)$ & $8(89)$ \\
\hline Optimal & $0(0)$ & $1(11)$ \\
\hline \multicolumn{3}{|l|}{ Highest level of education attained } \\
\hline Unfinished high school & - & $0(0)$ \\
\hline High school & - & $5(56)$ \\
\hline Professional school & - & $1(11)$ \\
\hline Entry-level college & - & $1(11)$ \\
\hline Graduate school & - & $2(22)$ \\
\hline
\end{tabular}

*Optimal participation $=$ Have participated to at least $80 \%$ of proposed interventions $;$ Average participation = Good overall participation, some refusal $;$ Low participation = Mostly refusals. 


\begin{tabular}{|lll|}
\hline Characteristics & $\begin{array}{l}\text { Adolescents }(\mathbf{n}=5) \\
\mathbf{n}(\%)\end{array}$ & $\begin{array}{l}\text { Parents }(\mathbf{n}=9) \\
\mathbf{n}(\%)\end{array}$ \\
\hline Marital status & - & $8(89)$ \\
Common-law partners or married & - & $1(11)$ \\
Separated & & \\
\hline $\begin{array}{l}* \text { Optimal participation = Have participated to at least 80\% of proposed interventions ; Average } \\
\text { participation = Good overall participation, some refusal ; Low participation = Mostly refusals. }\end{array}$ \\
\hline
\end{tabular}

\section{Themes}

Four themes were determined according to the frameworks used: (1) determinants of participation, (2) perceived benefits and behaviour change, (3) attitude towards health behaviours and intention to change, and (4) suggestions for improvement (Table 3). 
Table 3

Themes and subthemes

\begin{tabular}{|c|c|}
\hline \multicolumn{2}{|c|}{ Theme 1: Determinants of participation } \\
\hline \multirow[t]{5}{*}{ Barriers } & Time or organizational constraints (Inner setting) \\
\hline & Health issues (Personal characteristics) \\
\hline & Lack of need (Personal characteristics) \\
\hline & Lack of interest or motivation (Personal characteristics) \\
\hline & Perceived difficulty of the intervention, burden (Personal characteristics) \\
\hline \multirow[t]{6}{*}{ Facilitators } & Convenience (Inner setting) \\
\hline & Adaptability (Characteristics of intervention) \\
\hline & Positive relationships (Characteristics of intervention) \\
\hline & Perceived benefits (Personal characteristics) \\
\hline & Knowledge and beliefs about intervention (Personal characteristics) \\
\hline & Convenience (Inner setting) \\
\hline \multicolumn{2}{|c|}{ Theme 2: Behavioural beliefs and action } \\
\hline \multirow[t]{6}{*}{ Benefits of program } & Positive impact on their health behaviours \\
\hline & Improved physical and mental health \\
\hline & Brightened up days at the hospital \\
\hline & Improved knowledge \\
\hline & Social support \\
\hline & No benefit / change in behaviour \\
\hline \multicolumn{2}{|c|}{ Theme 3: Attitude and behavioural intent } \\
\hline \multirow[t]{2}{*}{ Long-term benefits } & Intention to change or sustain behaviour change \\
\hline & No benefit / intention to change behaviour \\
\hline \multicolumn{2}{|c|}{ Theme 4: Suggestions for future implementation } \\
\hline
\end{tabular}

\section{Theme 1: Determinants of participation}

Participants reported many barriers to participation. The most important barriers were time and organizational constraints, which related to the inner setting of the program. Other barriers related mostly 
to the personal characteristics of participants and included lack of interest or need, physical or mental health issues and perceived difficulty of the intervention or burden. Indeed, for some parents, feeling overwhelmed had hampered their participation:

"You know, of course it is very challenging, in a moment where... it is not going really well... when you know you have already lost balance and you are trying to get back on your feet and it is difficult... and you have homeworks given to you and you know you are going to have to... you are already psychologically exhausted and you have to do that on top of it... » (L., parent of a 5-year-old ${ }^{1}$ )

Age of participants was noted as an important factor impacting the level of participation and motivation of participants. Indeed, barriers related to personal characteristics, particularly lack of motivation, were reported mostly by adolescents. As one mother underlined: « if he had not been an old teenager, also [...], you know if he had been younger, like 10 or 12 years old, he probably would have felt the need to be active.» (N., parent of a 16-year-old).

Elements of the inner setting were also viewed as facilitators. First, participants had to wait long hours at the clinic and were happy to fill those hours with the program interventions. The facility and materials were easily accessible when the participants were at the hospital. Moreover, the interventions could be delivered remotely (i.e., Zoom meetings or telephone), which was viewed as very convenient, especially considering the COVID-19 pandemic that impacted the second half of the program. Characteristics of the interventions that were reported as facilitators were the flexibility and adaptability in the delivery of the program and the tailoring of the interventions to individuals' needs. Regarding personal characteristics, participants who had a good understanding of the potential benefits of the interventions or a positive attitude towards the adoption of healthy behaviours had a higher level of participation in the program.

Participants reported that the opinion of significant others, or the subjective norms according to the TPB, influenced their participation. Having positive relationships and trust in the research team members was a motivation for participating as well as including siblings or other family members in the interventions. Regarding opinion leaders, defined in the CIFR as individuals in an organization who have influence on attitudes and beliefs towards an intervention, most participants said they had received support from the clinical team to participate.

"I would say they were all in favor of [the VIE study]. When you talk to the nurses and all, they talk about it with interest... they are enthusiastic about this program... » (L., parent of a 13-year-old)

However, even though participants reported feeling supported by the clinical team, some participants did not feel like the health promotion activities were well integrated in the clinical care; for example, a participant considered that the research and clinical teams were disconnected, saying: "I thought that it was two different worlds" (I., parent of a 5-year-old). Moreover, one participant mentioned that having many different professionals involved made it difficult to build significant relationships and trust with everybody: 
"There are already so many stakeholders who gravitate that at some point, making effort everywhere, we become exhausted and hum... we struggle to see the added value of everybody " (P., parent of a 13-yearold)

\section{Theme 2: Perceived benefits and behaviour change}

Regarding the benefits of the program, most participants reported that it had a positive impact on some of their nutrition or physical activity health behaviour practices during cancer treatment. Participants also reported they felt that the program improved their overall physical and mental health and brightened up their days at the hospital.

"Of course, it helped me to sustain healthy behaviours. Doing some exercises, once in a while, things like that, because if I had only listened to myself... » (L., 16-year-old participant)

The TPB states that behavioural achievement depends on both motivation (i.e., intention) and ability (i.e., behavioural control). During cancer treatment, suffering from symptoms of cancer and side effects of treatment limits the perceived behavioural control of children and adolescents. For example, physical symptoms such as pain and fatigue limited the participation to physical activity interventions and nausea or cravings for unhealthy food limited the adoption of nutrition guidelines.

\section{Theme 3: Attitude towards health behaviours and intention to change}

Even though all participants reported having a positive attitude towards the adoption of healthy behaviours, only half of them mentioned having the intention to modify their health behaviour practices in the long-term. Indeed, half of the participants thought they would have long-term benefits from having participated in the program.

"I have seen the importance of being active... we will keep this new way of living" (K., parent of a 5-yearold)

The other half did not think participating in the program would make a difference in the long-term regarding their health behaviour practices.

"But I don't think that it will make a long-term difference. It did make a huge difference during the illness, though." (I., parent of a 5-year-old)

\section{Theme 4: Suggestions for improvement}

For refinements og the program, participants suggested various ways of improving it (Table 4). The most common suggestions were better integrate research intervention into clinical care and to include HP interventions in their daily clinical schedule. Other recommendations included increasing the frequency of physical activity interventions, adding more educational activities and providing online material such as exercise videos guided by the physical activity team members. A participant also suggested making the 
health promotion mandatory. In his opinion: "If it is that important to adopt healthy behaviours, well... it should not be done on a voluntary basis. It has to be part of the cancer treatment [...] more imposed than optional" (J., parent of a 4-year-old). 
Table 4

Suggestions for program improvement

\section{Themes Subthemes Quotations}

\begin{tabular}{|c|c|c|}
\hline \multirow{3}{*}{\multicolumn{2}{|c|}{ Interventions }} & $\begin{array}{l}\text { "What can be improved? Well of course, more sport" (C., parent of a } \\
\text { 4-year-old) }\end{array}$ \\
\hline & & $\begin{array}{l}\text { "It can be more often, or twice a week, you know. Twice a week } \\
\text { would be perfect. Having more." (L., parent of a 13-year-old) }\end{array}$ \\
\hline & & $\begin{array}{l}\text { "Maybe a little more of the sport component?"(D., parent of a 4- } \\
\text { year-old) }\end{array}$ \\
\hline & $\begin{array}{l}\text { Educational } \\
\text { activities }\end{array}$ & $\begin{array}{l}\text { "I think it could have helped me. Mostly, you know maybe less for } \\
\text { the kids of } 4 \text { or } 5 \text { years old. But, you know, I was } 18 \text { years old back } \\
\text { then. So I think it could have helped me to understand why I was } \\
\text { doing this, not just you to have to do it" (M., 18-year-old participant) }\end{array}$ \\
\hline & & $\begin{array}{l}\text { "Giving more explanation [...]. Especially at [my daughter]'s age, like } \\
13 \text { or more } 14 \text { when she was had it, she is able to comprehend a } \\
\text { lot, you know" (L., parent of a 13-year-old) }\end{array}$ \\
\hline
\end{tabular}

More tailored to specific needs

"Hum I would say, to respect more the physical limits of the patient" (L., 16-year-old participant)

"Maybe like a challenge... It could have been brought up differently, more like a game." (L., parent of a 13-year-old)

On-demand

"You know, little clips, that she could have done from home. And, online you know, maybe it would have helped her to move a little more, at material home also. You know, showing her siblings, "look dad this is what we did [at the hospital]" (I., parent of a 5-year-old)

Virtual interventions

"The part at home was giving us ideas, also, for us parents and for the kid on how to deal with what you have, you know. So I think it can be something that, well according to me it should stay on a regular basis" (L., parent of a 5-year-old)

Organizational factors
Better coordination with clinical activities
"Also a better coordination of all the resources" (P.I, parent of a 12year-old)

"It was not all the activities that were included in the schedule, like the other medical appointments. [...] A convergence of [both teams], if you want. It is part of your daily schedule" (J., parent of a 4-yearold).

"It is really important [to do the blood and stool testing for the project], but I would have prefered it to be scheduled with an appointment at the hospital and, maybe in collaboration with a clinical nurse" (L., parent of a 5-year-old)

"Maybe to try to reach the occupational therapist and physiotherapist at the same time? Yeah, I don't know. I don't know if it could work. Because at the same time, [my daughter] could have worked her limbs without thinking she is working?" (D., parent of a 4-year-old) 


\begin{tabular}{|c|c|c|}
\hline Themes & Subthemes & Quotations \\
\hline & Mandatory & $\begin{array}{l}\text { "If it is that important to adopt healthy behaviours, well... it should } \\
\text { not be done on a voluntary basis. It has to be part of the cancer } \\
\text { treatment [...] more imposed than optional" (J., parent of a 4-year- } \\
\text { old). }\end{array}$ \\
\hline & $\begin{array}{l}\text { Later in the } \\
\text { cancer } \\
\text { continuum }\end{array}$ & $\begin{array}{l}\text { "Maybe the timing was not good... I don't know, maybe more... Well, } \\
\text { I don't know how the other kids go through this and what type of } \\
\text { difficulties they face, but if [my daughter] would have needed more } \\
\text { help, support, advise of this type, it would have been [during } \\
\text { survivorship]" (P., parent of a 12-year-old) }\end{array}$ \\
\hline
\end{tabular}

${ }^{1}$ Age at diagnosis

\section{Discussion}

The purpose of this qualitative study was to analyse the perspective of children affected by cancer and their families in relation to their participation in a HP program. Several important results emerged from this study. A majority of participants reported that the program was beneficial during the cancer continuum; the most prominent benefits being the positive impact on 1) their health behaviour practices, 2 ) their physical and mental health as well as 3 ) their overall experience at the hospital. The main barriers to participation were 1) organizational barriers, 2) physical or mental health issues and 3) a lack of interest or need. In the long-term, only half of the participants have the intention to make sustainable change in their health behaviour practices as a result of their participation in the program.

In this study, the social context and enjoyment of the activities were important for the participants. This finding is supported by previous research demonstrating that fun during exercising was the main motivation during treatment for children with cancer [24] and that social interactions were important to the overall physical activity experience [25]. A facilitator identified in this study that should be kept in future initiatives is to have flexible, individualized interventions. It is thought to have helped overcome some of the barriers that were also reported in other studies, such as being too tired, too busy, afraid of injury, and having negative thoughts and feelings about themselves [26]. By addressing the specific needs of children and their families, including emotional support as well as adapting the timing, length and intensity of interventions, some of these barriers were most probably removed. As families affected by cancer are often disrupted and consumed by the intensity of cancer therapy [26, 27], another study has reported that such interventions are difficult to implement, especially around diagnosis, because of the complexity of initial cancer treatments and the difficulties in asking patients to take on even more than getting through their treatments [28]. Reinforcing the facilitators identified is therefore key to make the HP programs as enjoyable, convenient and individualized as possible. Similar to another study investigating the attitudes toward improving lifestyle behaviour after cancer treatment [29], adolescents in our study 
seemed to show less interest or motivation. Thus, developing targeted strategies for adolescents or additional support will be crucial in future initiatives.

Regarding program improvements, adding educational activities was suggested and could be one way to increase the intention to change of participants and parents. According to Gotte and et al. [24], educational work can be used to inform children affected by cancer and their families about how barriers such as lack of energy and bad mood can be influenced by physical activity and thus improve their participation. However, the importance of the « teachable moment » [28] has to be considered when deciding when to conduct this type of intervention to change one's behaviour. Educational strategies will have to be adapted to the different target groups (i.e., adolescents or parents). Also, adding more targeted, theory-base behaviour change strategies could help to meet the participants where they are in the change process and address their readiness to change, instead of prematurely, and possibly ineffectively, addressing the adoption of health behaviours. For example, providing an extensive training in motivational interviewing $[30,31]$ to staff or integrating Prochaska's stages of change in their practice could be helpful. Finally, future initiatives should put more emphasis on trying to better integrate HP interventions or programs in cancer care and to have the support from the clinical team.

Limitations of the study need to be considered when interpreting the findings. As a single-center study, the findings cannot be generalized to the pediatric cancer population, which may limit the transferability of the recommendations. There may also be some degree of selection bias in our sample; that is, individuals who accepted to be interviewed may differ in important ways from those who did not or from participants who dropped-out of the study. Furthermore, participants who enrolled in the VIE study were more likely to have a positive attitude towards healthy behaviours than non-participants Although most participants shared their perception of flaws in the research project or need for improvement, none had major complaints and we acknowledge that this may have limited participants' willingness to share negative experiences with us. Consequently, our data analysis is focused on improving behaviour change rather than on increasing the recruitment rate. Another limitation is the fact that the first author who conducted and analyzed the interviews was a member of the research team, which could have introduced bias such as social desirability. Regarding data analysis, it is possible that because of this close knowledge with the research team and how the research project was conducted, we inadvertently made assumptions regarding the data or missed important aspects of the phenomenon. This risk has been controlled by including a researcher who was not involved in the research project for data analysis.

Future studies should gather the perspective of participants who dropped out of the study or of nonparticipants to better understand how to adapt the program and increase its reach. As the aim was to analysethe perspective of participants who were enrolled in the program for at least a year and a half, those who had withdrawn were not eligible and it was deemed inappropriate to contact them. The next steps will be to analyse the perspectives of stakeholders regarding the program, to refine the program in order to meet the expressed needs and preferences of participants and stakeholders as well as to develop strategies aiming at eliminating the identified barriers and increasing the sustainability of participants' behaviour change. 


\section{Conclusion}

This study allows researchers and clinicians to gain greater insights into how to shape HP programs that will be engaging and effective in promoting healthy behaviours in this population. Participants' and families' perspective provide important directions for implementation and program refinement.

\section{Declarations}

\section{Acknowledgments}

This research was supported by the Fondation des Gouverneurs de l'Espoir. We also acknowledge the support of all the team members of the VIE study.

\section{Funding}

The main author was supported by the Fondation des Gouverneurs de l'Espoir. The VIE study was funded by the Fondation Charles Bruneau.

\section{Conflicts of interest/Competing interests}

The authors have no conflicts of interest to declare that are relevant to the content of this article and have no financial or non-financial interests to disclose.

\section{Availability of data and material}

All data and material support our published calms is available, if required.

\section{Code availability}

Code for software application is available, if required.

\section{Authors' contribution}

All authors contributed to the study conception and design. Material preparation, data collection was conducted by Catherine Demers. Data analysis was performed by Catherine Demers and Keven Lee. The first draft of the manuscript was written by Catherine Demers and all athors commented on previous versions of the manuscript. All authors read and approved the final manuscript.

\section{Ethics approval}

Ethical approval for this study was obtained from the SJUHC Research Ethics Board. Written informed consent was obtained from parents or adolescents $\geq 18$ years old and verbal consent was obtained for children and adolescents $<18$ years old. Data was anonymized.

\section{Consent to participate}


All participants gave their informed consent to participate.

\section{Consent for publication}

All participants gave their informed consent to having their data published.

\section{References}

1. Landier, W., S. Armenian, and S. Bhatia, Late effects of childhood cancer and its treatment. Pediatr Clin North Am, 2015. 62(1): p. 275-300.

2. Dickerman, J.D., The late effects of childhood cancer therapy. Pediatrics, 2007. 119(3): p. 554-68.

3. Galligan, A.J., Childhood Cancer Survivorship and Long-Term Outcomes. Adv Pediatr, 2017. 64(1): p. 133-169.

4. Lemay, V., et al., Prevention of Long-term Adverse Health Outcomes With Cardiorespiratory Fitness and Physical Activity in Childhood Acute Lymphoblastic Leukemia Survivors. J Pediatr Hematol Oncol, 2019. 41(7): p. e450-e458.

5. Robison, L.L. and M.M. Hudson, Survivors of childhood and adolescent cancer: life-long risks and responsibilities. Nat Rev Cancer, 2014. 14(1): p. 61-70.

6. Caru, M., et al., The VIE study: feasibility of a physical activity intervention in a multidisciplinary program in children with cancer. Support Care Cancer, 2020. 28(6): p. 2627-2636.

7. Beaulieu-Gagnon, S., et al., Nutrition education and cooking workshops for families of children with cancer: a feasibility study. BMC Nutr, 2019. 5: p. 52.

8. Hudson, M.M. and C. Patte, Education and health promotion in adolescent and young adult cancer survivors. Pediatr Blood Cancer, 2008. 50(5 Suppl): p. 1105-8.

9. Mertens, A.C., et al., Late mortality experience in five-year survivors of childhood and adolescent cancer: the Childhood Cancer Survivor Study. J Clin Oncol, 2001. 19(13): p. 3163-72.

10. Nottage, K.A., et al., Metabolic syndrome and cardiovascular risk among long-term survivors of acute lymphoblastic leukaemia - From the St. Jude Lifetime Cohort. Br J Haematol, 2014. 165(3): p. 36474.

11. Demark-Wahnefried, W., et al., Riding the crest of the teachable moment: promoting long-term health after the diagnosis of cancer. J Clin Oncol, 2005. 23(24): p. 5814-30.

12. Caru, M., et al., The impact of cancer on theory of planned behavior measures and physical activity levels during the first weeks following cancer diagnosis in children. Support Care Cancer, 2021. 29(2): p. 823-831.

13. Stössel, S., et al., Physical activity behaviour in children and adolescents before, during and after cancer treatment. Sport Sci Health, 2020(16): p. 347-353

14. Fuemmeler, B.F., et al., Diet, physical activity, and body composition changes during the first year of treatment for childhood acute leukemia and lymphoma. J Pediatr Hematol Oncol, 2013. 35(6): p. 437-43. 
15. Caru, M., et al., Children's physical activity behavior following a supervised physical activity program in pediatric oncology. J Cancer Res Clin Oncol, 2020. 146(11): p. 3037-3048.

16. Wurz, A., et al., Synthesizing the literature on physical activity among children and adolescents affected by cancer: evidence for the international Pediatric Oncology Exercise Guidelines (iPOEG). Transl Behav Med, 2021. 11(3): p. 699-708.

17. Demers, C., et al., Complex behavioral interventions targeting physical activity and dietary behaviors in pediatric oncology: A scoping review. Pediatr Blood Cancer, 2021: p. e29090.

18. Arroyave, W.D., et al., Childhood cancer survivors' perceived barriers to improving exercise and dietary behaviors. Oncol Nurs Forum, 2008. 35(1): p. 121-30.

19. Ste-Justine, C. Le Projet VIE : Valorisation - Implication - Éducation. 2021; Available from: https://www.chusj.org/fr/soins-services/H/Hematologie/Projet-Vie.

20. Ajzen, I., The theory of planned behaviour. Organizational Behavior and Humain Decision Processes, 1991. 50: p. 179-201.

21. Keats, M.R., et al., Understanding physical activity in adolescent cancer survivors: an application of the theory of planned behavior. Psychooncology, 2007. 16: p. 448-57.

22. Damschroder, L.J., et al., Fostering implementation of health services research findings into practice: a consolidated framework for advancing implementation science. Implement Sci, 2009. 4: p. 50.

23. Braun, V. and V. Clarke, Using thematic analysis in psychology. Qualitative Research in Psychology, 2006. 3(2): p. 77-101.

24. Gotte, M., et al., Experience of barriers and motivations for physical activities and exercise during treatment of pediatric patients with cancer. Pediatr Blood Cancer, 2014. 61(9): p. 1632-7.

25. Craike, M.J., et al., Perceived benefits and barriers to exercise for recently treated patients with multiple myeloma: a qualitative study. BMC Cancer, 2013. 13: p. 319.

26. Ross, W.L., et al., Physical activity barriers, preferences, and beliefs in childhood cancer patients. Support Care Cancer, 2018. 26(7): p. 2177-2184.

27. van Dijk-Lokkart, E.M., et al., Factors influencing childhood cancer patients to participate in a combined physical and psychosocial intervention program: Quality of Life in Motion.

Psychooncology, 2015. 24(4): p. 465-71.

28. Ganz, P.A., A teachable moment for oncologists: cancer survivors, 10 million strong and growing! J Clin Oncol, 2005. 23(24): p. 5458-60.

29. Touyz, L.M., et al., Childhood cancer survivors report preferring lifestyle interventions delivered in person rather than online: An adolescent and parent perspective. Pediatr Blood Cancer, 2019. 66(10): p. e27922.

30. Miller, W.R. and S. Rollnick, Motivational Interviewing: Preparing People To Change Addictive Behavior. 1991, New York: Guilford Press.

31. Dewez, S., et al., Elaboration and refinement of a motivational communication training program for healthcare professionals in pediatric oncology: a feasibility and acceptability study. Health Psychol 
Behav Med, 2021. 9(1): p. 220-238. 